\title{
Impact of a Low Preoperative Body Mass Index on the Postoperative Complications and Overall Survival of Gastric Cancer Patients: a Systematic Review and Meta-analysis
}

\author{
Huan Wang ${ }^{1}$, Chen Yu Mao ${ }^{1}$, Jing Deng ${ }^{1}, \mathrm{Xi} \mathrm{Jin}^{2}$, Nong Xu ${ }^{1}$ \\ ${ }^{I}$ Department of Medical Oncology, First Affiliated Hospital of Zhejiang University, Hangzhou, Zhejiang 310000, China; ${ }^{2}$ Department \\ of Gastroenterology, First Affiliated Hospital of Zhejiang University, Hangzhou, Zhejiang 310000, China
}

\begin{abstract}
Objective Obesity is related to various diseases and the risk of cancer. However, most studies overemphasize the risk of obesity, while ignoring the impact of underweight. In this study, we carried out a metaanalysis to assess the impact of a low preoperative body mass index on the postoperative complication and overall survival rates of gastric cancer patients. Methods We identified and selected relevant studies through PubMed, Embase, the Cochrane Library databases, the web of science, China National Knowledge Infrastructure and Wanfang electronic databases up to February 2019. The relative risk and $95 \%$ confidence interval were used to assess the association between the BMI and outcomes of gastric cancer patients. Results Seventeen publications were included in the final meta-analysis. There was a significant increase in the risk of postoperative complications (RR: 1.30, 95\% CI: 1.07 - 1.57, $P<0.05 ; I^{2}=61.1 \%$ ) in the patients with a low body mass index. Conclusion Further research, including larger-scale prospective studies, is needed to confirm this finding. For underweight patients with poor nutritional status, preoperative nutritional support and BMI adjustment may be helpful to improve the postoperative outcomes.
\end{abstract}

Key words: Gastric cancer; BMI; Postoperative complications; Prognosis; Meta-analysis

\section{Introduction}

Gastric cancer is one of the most common malignant tumors in the world and the third leading cause of morbidity and mortality [1]. It has been reported that preoperative malnutrition or a poor nutritional status are present in about $80 \%$ of patients with advanced gastric cancer [2]. Most underweight patients experience symptoms such as depression, apositia, hyperthyroidism, intestinal malabsorption and age-related muscle loss. Tumor growth can induce systemic inflammation and comorbid diseases, which may lead to excessive nutritional consumption [3].

It is well known that obesity is related to various diseases, including the risk of cancer. However, the risks associated with obesity are overemphasized, while ignoring the impact of underweight. Many studies have found an adverse influence of a low body mass index (BMI) on patients with gastric cancer $[4,5]$. Some researchers found that a low BMI in patients with gastric cancer was associated with a high risk of postoperative complications and overall survival (OS) [4,6-8]. However, others found no association [9-13]. In view of the contradictory conclusions, we performed a meta-analysis and tried to provide a more precise estimate of the association between a low preoperative BMI and the development of postoperative complications, as well as the long-term survival of gastric

Corresponding author: Nong Xu, MD, Department of Medical Oncology, First Affiliated Hospital of Zhejiang University, No.79, Qingchun Road, Shangcheng District, Hangzhou, Zhejiang 310000, China, Tel: 05718723 5896; Email: nongxu@zju.edu.cn. cancer patients.

\section{Methods \\ Literature search strategy}

We conducted a comprehensive search of electronic databases including PubMed, Embase, the Cochrane Library databases, the Web of Science, the China National Knowledge Infrastructure (CNKI) and the Wanfang databases up to February 2019. The key words used for the search were "gastric cancer", "stomach neoplasms", "gastrectomy", "underweight", "malnutrition" and "BMI". The following search terms were employed to retrieve the relevant literature from the databases: (gastric cancer OR stomach neoplasms OR gastrectomy) AND (underweight OR malnutrition OR body mass index OR BMI). The search strategy was changed according to different requirements with English and Chinese language restrictions. The published literature was selected from February 1985 to February 2019. Publications were initially filtered by reviewing the title and abstract of all citations and retrieved literature. At the same time, the retrieved reference lists were also reviewed to identify additional relevant studies manually. When multiple studies published the same or overlapping datasets, we considered only the most informative or the most recent publication.

\section{Inclusion and exclusion criteria}

The included studies had to meet the following criteria: (1) All gastric cancer patients with gastrectomy with a diagnosis based on pathological findings. (2) According 
to the recommendations of the World Health Organization (WHO), a preoperative BMI $<18.5$ was defined as underweight and a BMI 18.5 24.9 was defined as normal weight. The classification of patients was defined by this BMI criterion. (3) All included studies were case-control and cohort studies. The outcome of postoperative complications and/or survival had to be included in the study. It had to be possible to determine the OS and corresponding 95\% confidence intervals (CI) from the included data. (4) The postoperative complications should have been recorded, including anastomotic leakage, intraperitoneal infection, pulmonary infection, wound infection and intra-abdominal infection. (5) If multiple studies derived from the same research institution or author group were identified, only the most informative or highest quality was selected. Conference abstracts and reports were excluded due to the inadequate data and insufficient information.

\section{Data extraction and quality assessment}

According to the pre-specified selection criteria, data were extracted from the included publications by two reviewers working independently. Decision were made and disagreements about study selection were resolved through consensus or by involving a third reviewer. The following information and data were extracted and gathered from each included study: first author, year of publication, country where the study was carried out, study period, sample size, median or mean age, gender of participants, duration of follow-up, TNM (tumor node metastasis) staging, cut-off value used for the BMI, length of the operation, number of retrieved lymph nodes, amount of intraoperative blood loss, postoperative complications, postoperative mortality, length of hospital stay, and OS.

Two reviewers independently assessed the methodological quality of the included studies using the Newcastle-Ottawa quality assessment scale (NOS) [14,15]. The NOS included three points: the selection of the publications, the comparability of the study groups and the outcome(s). Every included publication was assigned a score. Nine points was the maximum NOS score possible, and reflected the highest quality study. Studies with NOS scores $\geq 6$ points were regarded as being high quality [16], and only these studies were included in the present metaanalysis. Any disagreements were discussed and resolved by a joint reevaluation with a third reviewer.

\section{Statistical analysis}

The dichotomous data were recorded as numbers, rates or proportions, and continuous data were recorded as medians or means and standard deviations. The continuous data were evaluated using the weighted mean difference (WMD) and 95\% CIs, and the risk of postoperative complications was evaluated using RRs and 95\% CIs. The heterogeneity was checked by the Cochran $Q$ test and $I^{2}$ statistic (significance level $I^{2}>50 \%$ and/or $P<0.1$ ). The pooled RRs with 95\% CI were calculated by a random effects model; otherwise, a fixed effects model was used. Possible publication bias was tested by Begg's funnel plot and Egger's test (significance level $P<0.05$ ). The MantelHaenszel $(\mathrm{M}-\mathrm{H})$ and Inverse Variance methods were used in a fixed effects model and a random effects model, respectively. Subgroup analyses were conducted based on the geographic area (Asian vs. Non-Asian) to explore potential sources of heterogeneity. All statistical analyses were performed in the STATA version 14.0 software.

\section{Results}

\section{Search results and study characteristics}

Figure 1 presents a flow chart showing the study selection process. A total of 567 potential studies relevant to the key words were initially identified through database and manual searches. Four hundred and eighty irrelevant studies were excluded after the title and abstract screening, and the remaining 87 studies were subjected to further fulltext review. Of these 87 studies, 70 were removed due to data duplication, incomplete information, inconsistent cutoff values for BMI or missing/unavailable data. Finally, 17 eligible studies were included in this meta-analysis. All included studies were published between 2008 and 2019, with sample sizes ranging from 73 to 12,626. Among these studies, 6 studies were from Japan, 3 studies were from Korea, 7 studies were from China, 2 studies were from the United States and one study was from Europe. The researched periods ranged from 1997 to 2016. The main characteristics of all included studies are given in the Table 1.

\section{Impact of the preoperative weight status on the surgical outcomes of gastric cancer patients}

We first assessed the influence of underweight on the length of the operation, the number of retrieved lymph nodes and the amount of intraoperative blood loss. Data about the length of the operation were reported in 5 studies. The pooled results showed that low BMI patients had shorter operation times than other patients (WMD: -17.26 , 95\% CI: -21.43 to $-13.09, P<0.001 ; I^{2}=0 \%$ ). There were not significant differences between patients with a low BMI and a normal BMI with regard to the number of retrieved lymph nodes (WMD: 0.52 , 95\% CI: -0.39 to $1.42, P<$ $\left.0.05 ; I^{2}=52 \%\right)$. A total of 4 studies investigated the effects of a low BMI on the intraoperative blood loss. The results indicated that there was a significant association between the amount of intraoperative blood loss and a low BMI (WMD: $-61.52,95 \%$ CI: -113.63 to $-9.41, P<0.05 ; I^{2}=0 \%$ ) (Table 2).

\section{Impact of a low BMI on the postoperative findings of gastric cancer patients}

Figure 2 reveals that there was a significantly increased risk of postoperative complications in patients with a low BMI (RR: $1.30,95 \%$ CI: 1.07 to $1.57, P<0.05 ; I^{2}=61.1 \%$ ), 


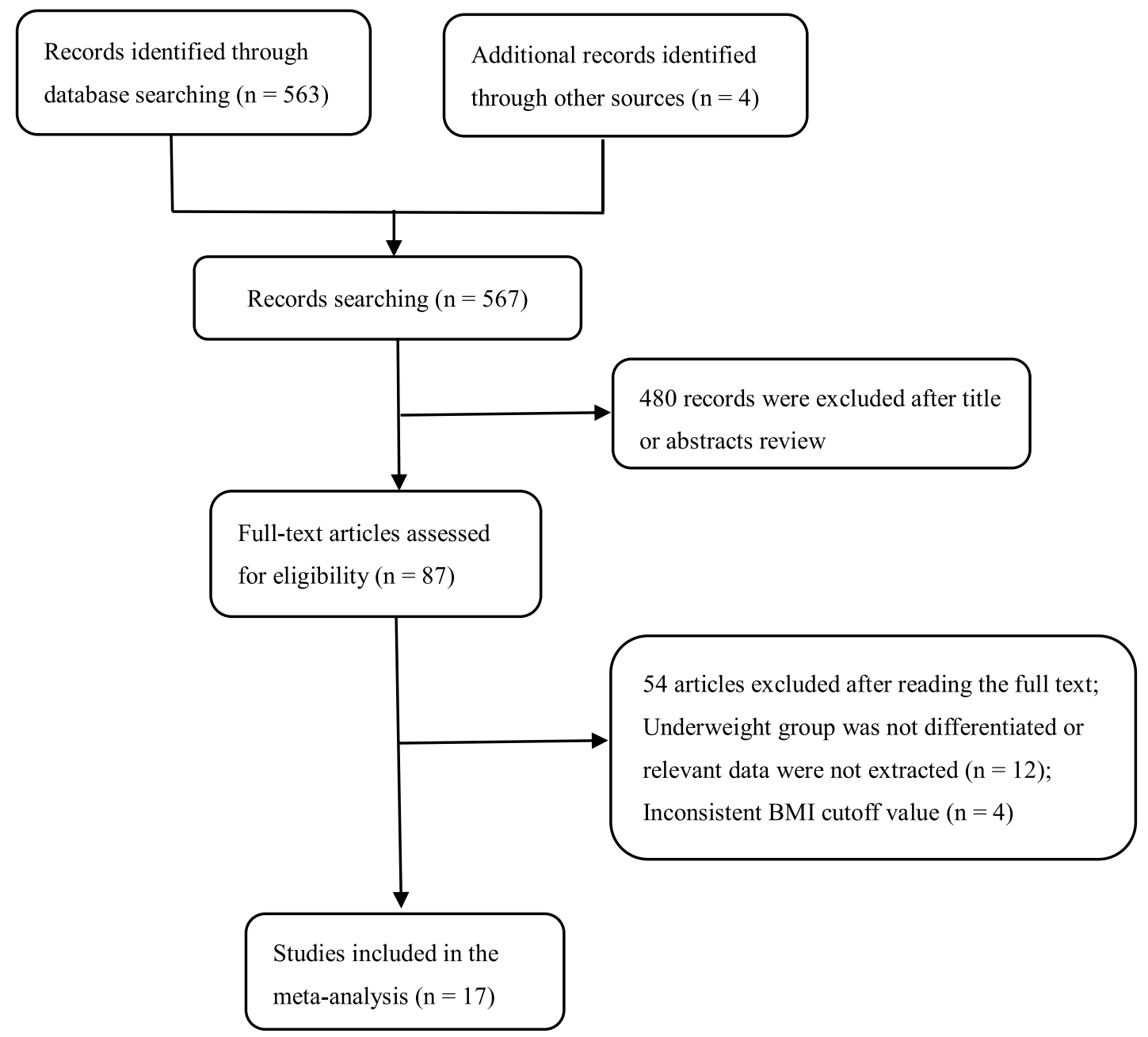

Figure 1 The flow diagram of the study selection.

especially for pulmonary infections (RR: 1.63, 95\% CI: 1.08 to $2.45, P<0.05 ; I^{2}=31.7 \%$ ). However, the incidence of other complications, such as anastomotic leakage, wound complications, and intra-abdominal infection, were not significantly different between the two patient groups (Table 2).

Four studies assessed the association between a low BMI and postoperative mortality. The results indicated that patients who were underweight had a higher risk of inhospital death (RR: 2.06, 95\% CI: 1.44 to $2.96, P<0.05$; $I^{2}=0 \%$ ) (Table 2). Four studies also provided data about the length of the hospital stay. However, we did not find any significant link between a low BMI and the length of hospital stay (WMD: $-0.20,95 \% \mathrm{CI}:-1.16$ to $0.77, P<0.05$; $I^{2}=0 \%$ ) (Table 2).

In addition to the postoperative complications and shortterm survival, we investigated the impact of a low BMI on the OS of gastric cancer patients. A total of 10 articles were included for the analysis of the OS. The pooled results demonstrated that underweight status had a negative impact on the prognosis of GC patients (RR: $0.88,95 \% \mathrm{CI}: 0.72$ to $1.07, P<0.05 ; I^{2}=89.6 \%$ ) (Figure 3 ).

\section{Publication bias}

No significant asymmetry was observed in the funnel plots. The Egger's test indicated that there was no evidence of publication bias among the studies of postoperative complications (Figure 4). The pooled results for the risk of postoperative complications were thus unlikely to be explained by publication bias. The $P$-values of the Egger's test for other results are presented in Table 2.

\section{Discussion}

It has been reported that the BMI was related to a negative prognosis for patients with colorectal cancer [17] and breast cancer [18], but the relationships between the BMI and the outcomes of patients with various cancers have not been confirmed. In regard to gastric carcinoma, there have been some cohort analyses that attached importance to the BMI for predicting a worse [19] or better [20] result. To date, it has been unclear whether a low BMI affects the postoperative complication and OS rates in these patients.

In the present study, we performed a systematic review and meta-analysis to compare and assess the risks of a low BMI on the postoperative complication and OS rates 
Table 1 Main characteristics of the 17 studies included in the meta-analysis.

\begin{tabular}{|c|c|c|c|c|c|c|c|c|c|c|c|c|}
\hline$\overline{\text { Study }}$ & Country & $\begin{array}{c}\text { Publication } \\
\text { year }\end{array}$ & $\begin{array}{c}\text { Inclusion } \\
\text { period }\end{array}$ & $\begin{array}{l}\text { Study } \\
\text { design }\end{array}$ & $\begin{array}{c}\text { Sample size } \\
\text { (L/M) }\end{array}$ & $\begin{array}{c}\text { Age median } \\
(\text { mean } \pm \text { SD) }\end{array}$ & $\begin{array}{l}\text { Gender } \\
(\mathrm{M} / \mathrm{F})\end{array}$ & $\begin{array}{c}\text { Type of } \\
\text { gastrectomy }\end{array}$ & $\begin{array}{l}\text { TNM } \\
\text { stage }\end{array}$ & $\begin{array}{c}\text { Follow-up } \\
\text { median } \\
\text { (range) }\end{array}$ & $\begin{array}{c}\text { Survival } \\
\text { data } \\
\text { (5-OS: } \\
\text { L vs N) }\end{array}$ & $\begin{array}{l}\text { Qual- } \\
\text { ity }\end{array}$ \\
\hline $\begin{array}{l}\text { Chen } \\
{[26]}\end{array}$ & China & 2015 & $2000-2010$ & $\begin{array}{l}\text { cohort } \\
\text { study }\end{array}$ & $\begin{array}{c}1066 \\
(158 / 908)\end{array}$ & $\begin{array}{l}\text { L: } 57(26-85) ; \\
\text { N: } 58(21-86)\end{array}$ & $768 / 298$ & $\begin{array}{l}\text { Open, } \\
\text { D1/D2 }\end{array}$ & I-IV & N/A & $\begin{array}{c}39.4 \% \text { vs } \\
50.8 \%\end{array}$ & 7 \\
\hline $\begin{array}{l}\text { Ejaz } \\
{[24]}\end{array}$ & USA & 2015 & $2000-2012$ & $\begin{array}{l}\text { cohort } \\
\text { study }\end{array}$ & $\begin{array}{c}393 \\
(55 / 338)\end{array}$ & $\begin{array}{l}\text { L: } 67.7 ; \\
\text { N: } 65.8\end{array}$ & $222 / 171$ & $\begin{array}{l}\text { Open, } \\
\text { D1/D2 }\end{array}$ & I-III & 35.9 & $\begin{array}{c}13.4 \% \text { vs } \\
36 \%\end{array}$ & 7 \\
\hline $\begin{array}{l}\text { Feng } \\
\text { [7] }\end{array}$ & China & 2018 & 2008-2015 & $\begin{array}{l}\text { cohort } \\
\text { study }\end{array}$ & $\begin{array}{c}520 \\
(104 / 416)\end{array}$ & $\begin{array}{c}59 \\
(20-87)\end{array}$ & $413 / 107$ & Open, D2 & I-III & $\begin{array}{c}25 \\
(1.6 \pm 74.6)\end{array}$ & N/A & 8 \\
\hline $\begin{array}{l}\text { Kambara } \\
{[4]}\end{array}$ & Japan & 2019 & $2005-2014$ & $\begin{array}{l}\text { cohort } \\
\text { study }\end{array}$ & $\begin{array}{c}384 \\
(64-320)\end{array}$ & $\begin{array}{c}67.8 \pm 10.1 \\
(31-88)\end{array}$ & N/A & Open & II-III & $\begin{array}{c}34.4 \\
(12-63)\end{array}$ & $\begin{array}{c}50.1 \% \text { vs } \\
62.5 \%\end{array}$ & 8 \\
\hline $\begin{array}{l}\text { Kim } \\
{[11]}\end{array}$ & Korea & 2014 & 2005-2008 & $\begin{array}{l}\text { cohort } \\
\text { study }\end{array}$ & $\begin{array}{c}220 \\
(22 / 108)\end{array}$ & $\begin{array}{l}\text { L: } 58 \\
\text { N: } 59\end{array}$ & $151 / 71$ & $\begin{array}{l}\text { Open, } \\
\text { D1/D2 }\end{array}$ & I-III & $\begin{array}{c}59.5 \\
(8-97)\end{array}$ & $\begin{array}{c}66.1 \% \text { vs } \\
80 \%\end{array}$ & 7 \\
\hline $\begin{array}{l}\text { Lee } \\
{[10]}\end{array}$ & Korea & 2016 & $2000-2008$ & $\begin{array}{l}\text { cohort } \\
\text { study }\end{array}$ & $\begin{array}{c}1460 \\
(121 / 1339)\end{array}$ & $58.3 \pm 11.8$ & N/A & Open & I-IV & $69.6 \pm 38.4$ & $\begin{array}{c}69.1 \% \text { vs } \\
74.2 \%\end{array}$ & 7 \\
\hline $\begin{array}{r}\text { Lee } \\
{[6]}\end{array}$ & Korea & 2018 & $2000-2016$ & $\begin{array}{l}\text { cohort } \\
\text { study }\end{array}$ & $\begin{array}{c}5154 \\
(229 / 4925)\end{array}$ & $58.6 \pm 11.9$ & $3434 / 790$ & Open & I-III & $\begin{array}{c}83.05 \\
(1.02 \pm 186.97)\end{array}$ & N/A & 9 \\
\hline $\begin{array}{l}\mathrm{Li} \\
{[9]}\end{array}$ & China & 2017 & 2011-2013 & $\begin{array}{l}\text { cohort } \\
\text { study }\end{array}$ & $\begin{array}{c}264 \\
(64-200)\end{array}$ & $55.2 \pm 10.5$ & $189 / 75$ & Open & I-III & $\begin{array}{l}36.1 \pm 18.9 \\
(0.7-64.9)\end{array}$ & N/A & 9 \\
\hline $\begin{array}{l}\mathrm{Li} \\
{[13]}\end{array}$ & China & 2015 & $2005-2010$ & $\begin{array}{l}\text { cohort } \\
\text { study }\end{array}$ & $\begin{array}{c}124 \\
(12 / 112)\end{array}$ & $\begin{array}{c}59 \\
(42-76)\end{array}$ & $102 / 22$ & Open & I-IV & N/A & $45.23 \%$ & 7 \\
\hline $\begin{array}{l}\text { Migita } \\
\text { [32] }\end{array}$ & Japan & 2016 & 2003-2011 & $\begin{array}{l}\text { cohort } \\
\text { study }\end{array}$ & $\begin{array}{c}504 \\
(73 / 431)\end{array}$ & $\begin{array}{l}\text { L: } 67.6 \pm 12.3 ; \\
\text { N: } 67.1 \pm 10.5\end{array}$ & $360 / 144$ & Open & I-III & 50.6 & $\begin{array}{c}66.6 \% \text { vs } \\
81.3 \%\end{array}$ & 7 \\
\hline $\begin{array}{l}\text { Minami } \\
{[25]}\end{array}$ & Japan & 2015 & $1997-2005$ & $\begin{array}{l}\text { cohort } \\
\text { study }\end{array}$ & $\begin{array}{c}772 \\
(82 / 690)\end{array}$ & $65.8 \pm 11.3$ & N/A & Open & I-IV & N/A & N/A & 8 \\
\hline $\begin{array}{l}\text { Nozoe } \\
{[30]}\end{array}$ & Japan & 2012 & $1998-2010$ & $\begin{array}{l}\text { cohort } \\
\text { study }\end{array}$ & $\begin{array}{c}264 \\
(47 / 217)\end{array}$ & $\begin{array}{c}\text { L: } 66 \pm 13.4 ; \\
\text { N: } 68.2 \pm 10.3\end{array}$ & $189 / 75$ & $\begin{array}{l}\text { Open, } \\
\text { D1/D2 }\end{array}$ & I-IV & N/A & N/A & 6 \\
\hline $\begin{array}{l}\text { Pacelli } \\
{[5]}\end{array}$ & Italy & 2008 & $2000-2006$ & $\begin{array}{l}\text { cohort } \\
\text { study }\end{array}$ & $\begin{array}{c}102 \\
(17 / 85)\end{array}$ & $\begin{array}{c}66.5 \pm 11.6 \\
(32-91)\end{array}$ & N/A & $\begin{array}{l}\text { Open, } \\
\text { D2/D3 }\end{array}$ & I-IV & N/A & N/A & 6 \\
\hline $\begin{array}{l}\text { Wada } \\
{[8]}\end{array}$ & Japan & 2015 & $2001-2005$ & $\begin{array}{l}\text { cohort } \\
\text { study }\end{array}$ & $\begin{array}{c}342 \\
(42 / 300)\end{array}$ & N/A & $104 / 238$ & Open & I-IV & $\begin{array}{c}61.4 \\
(1-135)\end{array}$ & $\begin{array}{c}42.6 \% \text { vs } \\
69.6 \%\end{array}$ & 7 \\
\hline $\begin{array}{l}\text { Wong } \\
{[14]}\end{array}$ & USA & 2014 & $1997-2012$ & $\begin{array}{l}\text { cohort } \\
\text { study }\end{array}$ & $\begin{array}{c}81 \\
(9 / 72)\end{array}$ & N/A & N/A & Open & I-III & $\begin{array}{c}36 \\
(0.4-120)\end{array}$ & $\begin{array}{l}\text { Median: } \\
21 \text { vs } 13\end{array}$ & 7 \\
\hline $\begin{array}{l}\text { Yasunaga } \\
{[27]}\end{array}$ & Japan & 2013 & 2010 & $\begin{array}{l}\text { cohort } \\
\text { study }\end{array}$ & $\begin{array}{c}12626 \\
(2000 / 10626)\end{array}$ & $69.1 \pm 11$ & N/A & N/A & I-III & N/A & N/A & 6 \\
\hline $\begin{array}{l}\text { Zhang } \\
{[12]}\end{array}$ & China & 2016 & 2010 & $\begin{array}{l}\text { cohort } \\
\text { study }\end{array}$ & $\begin{array}{c}118 \\
(23 / 95)\end{array}$ & $\begin{array}{l}\mathrm{L}: 69.9 \pm 5.0 \\
\mathrm{~N}: 63.0 \pm 1.9\end{array}$ & N/A & Open, D2 & I-IV & N/A & $\begin{array}{c}43.5 \% \mathrm{VS} \\
50.5 \%\end{array}$ & 7 \\
\hline
\end{tabular}

Table 2 Impact of the preoperative underweight status on the surgical outcomes and postoperative complications.

\begin{tabular}{|c|c|c|c|c|c|c|}
\hline Outcome & $\begin{array}{c}\text { Egger's test } \\
(P)\end{array}$ & No. of studies & Effect size (95\% CI) & $P$ value & $\begin{array}{c}\text { Heterogeneity } \\
\left(I^{2}\right)\end{array}$ & $P$ value \\
\hline \multicolumn{7}{|l|}{ Surgical outcomes } \\
\hline operation time(min) & 0.743 & 5 & WMD:-17.26 [-21.43, -13.09] & $<0.001$ & $0 \%$ & 0.600 \\
\hline retrieved lymph nodes & 0.139 & 4 & WMD: $0.52[-0.39,1.42]$ & 0.26 & $52 \%$ & 0.100 \\
\hline intraoperative blood loss & 0.66 & 4 & WMD:-61.52 [-113.63, -9.41] & 0.02 & $0 \%$ & 0.420 \\
\hline \multicolumn{7}{|c|}{ Postoperative complications } \\
\hline overall complications & 0.29 & 12 & RR: $1.30[1.07,1.57]$ & 0.008 & $61 \%$ & 0.003 \\
\hline anastomotic leakage & 0.018 & 7 & RR: $1.36[0.34,5.42]$ & 0.67 & $81 \%$ & $<0.001$ \\
\hline wound complications & 0.774 & 5 & RR: $0.97[0.58,1.63]$ & 0.92 & $0 \%$ & 0.970 \\
\hline pulmonary infection & 0.535 & 5 & RR: $1.63[0.90,2.97]$ & 0.11 & $31 \%$ & 0.210 \\
\hline intra-abdominal infection & 0.521 & 4 & RR: $1.26[0.54,2.97]$ & 0.6 & $0 \%$ & 0.760 \\
\hline in-hospital death & 0.478 & 4 & RR: $2.11[1.47,3.04]$ & $<0.001$ & $0 \%$ & 0.530 \\
\hline length of hospital stay & l & 2 & WMD:-0.20 [-1.16, 0.77] & 0.69 & $0 \%$ & 0.970 \\
\hline
\end{tabular}




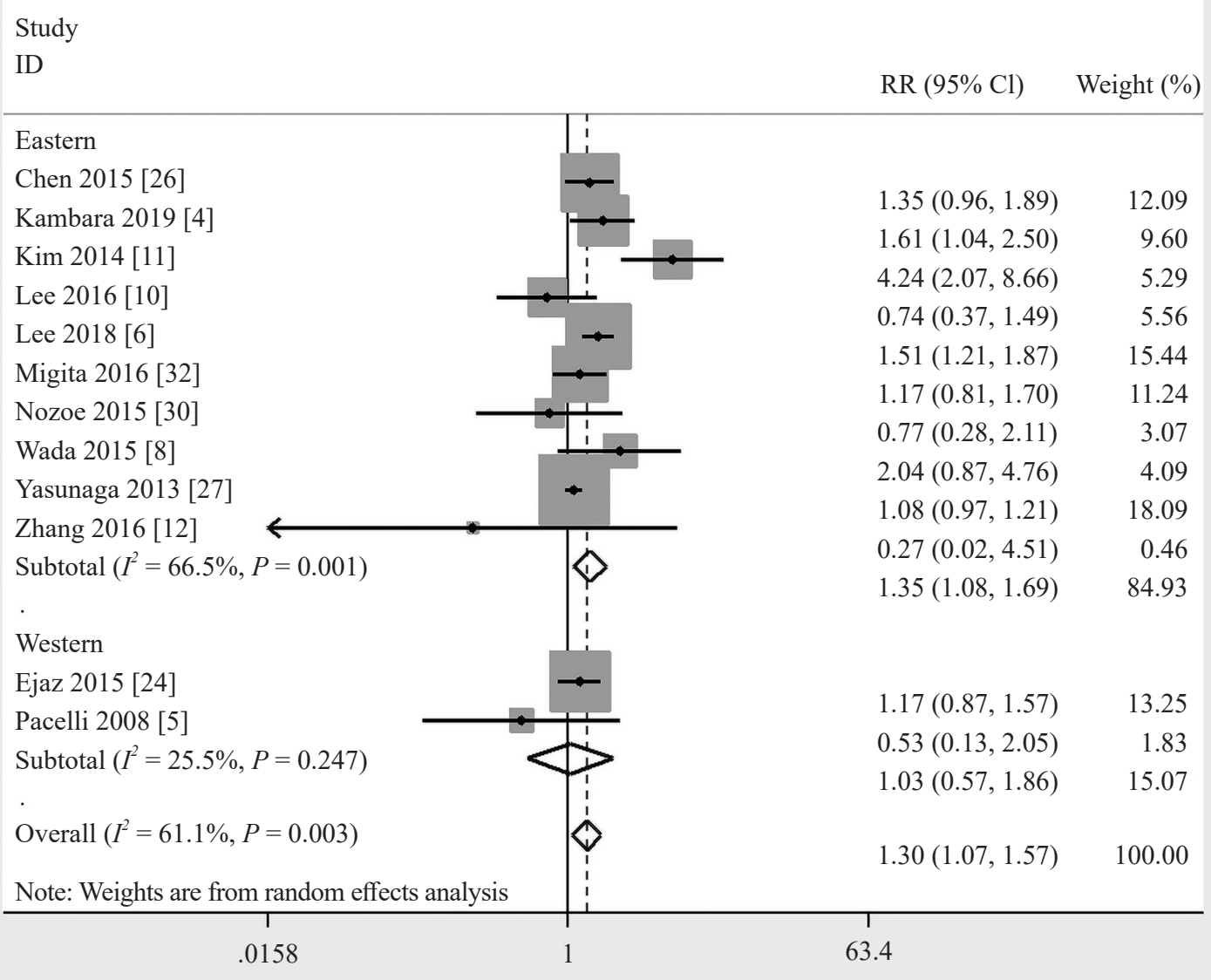

Figure 2 Forest plots of the impact of preoperative underweight status $(\mathrm{BMI}<\mathbf{1 8 . 5})$ on the postoperative complications.

in gastric cancer patients. The results showed that there was a significant relationship between a low BMI and postoperative complications, with these patients having a higher risk than normal weight patients. In addition, the low BMI patients had a poorer OS compared to normal weight patients.

The increased risk of postoperative complications may be attributed to the several causes. First, intraoperative blood loss and other surgical procedures could increase the risk of infections, pneumonia, anastomotic leakage and other complications, especially for elderly patients and those with other complications or comorbid diseases. Second, underweight patients with tumors are more likely to have clinical conditions such as depression, starvation, hyperthyroidism, malabsorption, and age-related muscle loss. Insulin resistance and immune suppression also negatively affect the rates of postoperative complications, which further causes a reduction in food intake, and together with hyper-catabolism, this can aggravate weight loss and may lead to cachexia [21]. Because of the pyloric obstruction and long-term bedridden status of individuals before gastrectomy, gastric cancer patients have a high prevalence of malnutrition or a poor nutritional status [22]. All of these can lead to postoperative complications. However, it remains controversial whether postoperative complications can be used as a prognostic factor. Even among the included studies, Ejaz A et al. reported that the BMI was not associated with postoperative complications [23]. However, several studies suggested that the patients in the low-BMI group had a higher rate of advanced disease [8,24-26]. There were confounding factors, which may have led to the contradictory findings of the different studies. In addition, some studies indicated that laparoscopic gastrectomy was more safely performed by experienced surgeons compared with open radical gastrectomy, and laparoscopy decreased the risk of postoperative complications, particularly pulmonary infections, as well as shortening the in-hospital stay for patients with preoperative malnutrition [27].

In the present study, the results suggested that there was no significant relationship between a low BMI and the OS. It was previously reported that underweight patients have a five-fold increased risk of postoperative mortality due to their underlying nutritional status [28]. However, this negative relationship was not observed in other studies [5,9$11,13,29]$. The reason may be that the low BMI patients had a shorter operation time and less blood loss than other patients. In addition, a higher risk of in-hospital death was observed in underweight patients. 
Study

ID
$\mathrm{RR}(95 \% \mathrm{Cl}) \quad$ Weight $(\%)$

Figure 3 Forest plots showing the impact of preoperative underweight status on the overall survival of gastric cancer patients.

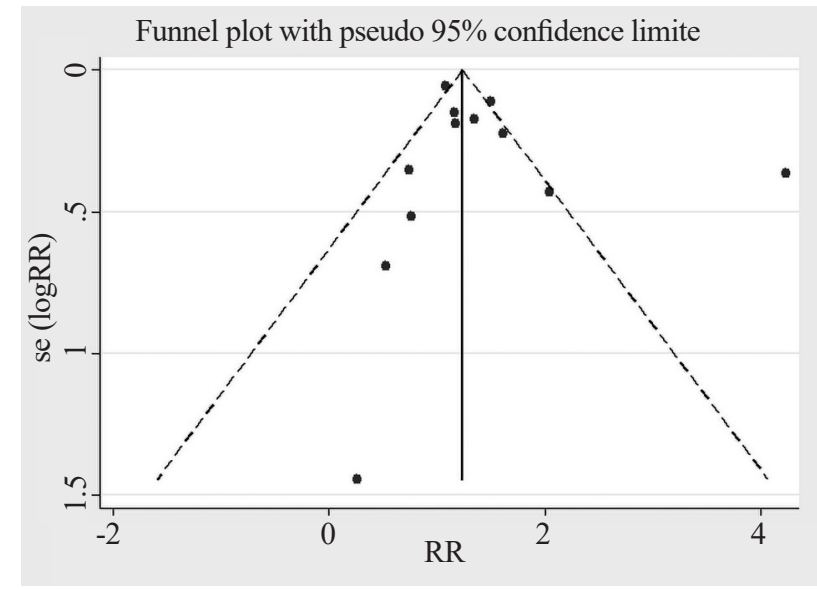

Figure 4 A funnel plot for the analysis of postoperative complications.

Stomach cancer was significantly associated with an increased risk of all-cause death among patients under 60 years of age, especially for those with a family history of the disease [24]. A cohort study reported that postoperative complications delayed the time to chemotherapy [30]. Another study indicated that low BMI status increased the risk of noncancer heath deficits [31]. Thus, the underweight status may have contributed to the increased postoperative complications and in-hospital death, and maybe even to the tumor growth and related immunological suppression.

In our meta-analysis, a considerable degree of heterogeneity was observed among the included studies. The definitions and severity of postoperative complications were different in some studies, and not all studies used the Clavien-Dindo classification to evaluate the postoperative complications. These differences may be a source of the high heterogeneity. In addition, a subgroup analysis indicated that the pooled analysis of postoperative complications could have been influenced by the geographic area. Significant heterogeneity was observed in subgroups from non-Asians (RR: 1.03, 95\% CI: 0.57 1.86, $P=0.93 ; I^{2}=25.5 \%$ ) and Asians (RR: $1.35,95 \% \mathrm{CI}$ : $\left.1.08 \sim 1.69, P<0.05 ; I^{2}=66.5 \%\right)$. The subgroup analysis found that the pooled results for the OS were similarly influenced by the geographic area (non-Asian: RR: 0.35 , 95\% CI: $0.18 \sim 0.69, P<0.05 ; I^{2}=0 \%$; Asian: RR: 0.93, 95\% CI: $\left.0.76 \sim 1.12, P=0.44 ; I^{2}=90.8 \%\right)$. The high heterogeneity in the pooled analysis of survival outcome may also have been due to the differences in tumor stage (not all studies had excluded gastric cancer patients with stage IV disease), patient characteristics (e.g., age, gender, and race), and the use of adjuvant chemotherapy. 
Moreover, the presence of comorbid diseases, the performance status, and other tumor-related factors were not uniformly considered among the different studies, which may have resulted in significant heterogeneity. The majority of the included studies were retrospective cohort studies, so the results could have been influenced by some unmeasured factors, such as selection bias, the surgical skills of the clinicians, different operation criteria, different surgical methods, and so on. Due to the high heterogeneity among the studies, we had to use a random effects model with broader $95 \%$ CIs to conservatively evaluate the impact of preoperative underweight status on the postoperative outcome. In the future, better designed, larger, multiple-center studies will be needed to clarify the potential association.

This study also has other limitations. First, metaanalyses are limited by the inherent bias and defects of the original literature. Second, the majority of studies included in this study were from China, Japan and Korea. The results of this study may not be applicable to nonAsian populations. Third, all of the included studies were retrospective studies. In addition, the sample size of some studies was small, which may have influenced the results of this study. Fourth, the definition of postoperative complications and postoperative discharge conditions were not unified. The presence of statistical errors may have led to bias. Fifth, we did not have access to the individualized data from all included studies. Therefore, the baseline characteristics between underweight patients and normal weight patients were not adjusted, which may have affected the pooled results.

In summary, the results indicated that a low BMI was associated with the risk of postoperative complications among gastric cancer patients. Despite the increased postoperative complications, the gastric cancer patients with underweight status did not show any reduction in the OS compared to patients with a normal body weight. However, further research is needed due to the inherent limitations of the present study. For underweight patients with a poor nutritional status, preoperative nutritional support and BMI adjustment may be helpful to improve the postoperative outcome.

\section{Conflict of Interests}

The authors declare no conflicts of interest.

\section{Funding}

This study was funded by a Zhejiang Provincial Science and Technology Project (No. 2014C03040-2), the National Health, Family Planning Commission Research Fund \& Zhejiang Provincial Medical and Health Major Science and Technology Plan Project (No. KWJ-ZJ-1802), and the Zhejiang Provincial National Science Foundation of China (No. LY16H160008).

\section{References}

1. Torre LA, Bray F, Siegel RL, Ferlay J, Lortet-Tieulent J, Jemal A. Global cancer statistics, 2012. CA Cancer J Clin 2015;65(2):87-108.

2. Rosania R, Chiapponi C, Malfertheiner P, Venerito M. Nutrition in Patients with Gastric Cancer: An Update. Gastrointest tumors 2016;2(4):178-87.

3. Schcolnik-Cabrera A, Chavez-Blanco A, Dominguez-Gomez G, Duenas-Gonzalez A. Understanding tumor anabolism and patient catabolism in cancer-associated cachexia. Am J Cancer Res 2017;7(5)110735.

4. Kambara Y, Yuasa N, Takeuchi E, et al. Overweight or obesity is an unfavorable long-term prognostic factor for patients who underwent gastrectomy for stage II/III gastric cancer. Overweight or Obesity is an Unfavorable Long-Term Prognostic Factor for Patients who Underwent Gastrectomy for Stage II/III Gastric Cancer 2019;43(7):1766-76.

5. Pacelli F, Bossola M, Rosa F, Tortorelli AP, Papa V, Doglietto GB. Is malnutrition still a risk factor of postoperative complications in gastric cancer surgery? Clin Nutr 2008;27(3):398-407.

6. Lee JH, Park B, Joo J, Kook MC, Kim YI, Lee JY, Kim CG, Choi IJ, Eom BW, Yoon HM, Ryu KW, Kim YW, Cho SJ. Body mass index and mortality in patients with gastric cancer: a large cohort study. Gastric cancer 2018;21(6):913-24

7. Feng F, Zheng G, Guo X, Liu Z, Xu G, Wang F, Wang Q, Guo M, Lian X, Zhang H. Impact of body mass index on surgical outcomes of gastric cancer. BMC cancer 2018;18(1):151.

8. Wada T, Kunisaki C, Ono HA, Makino H, Akiyama H, Endo I. Implications of BMI for the prognosis of gastric cancer among the Japanese population. Dig Surg 2015;32(6):480-6.

9. Li C, Shi Y, Guo X, Fan M, Yang L, Dai G. Impact of preoperative and postoperative body mass index on disease-free survival after resection for gastric cancer. Int J Clin Exp Med 2017;10(4):6167-75.

10. Lee HH, Park JM, Song KY, Choi MG, Park CH. Survival impact of postoperative body mass index in gastric cancer patients undergoing gastrectomy. Eur J Cancer 2016;52:129-37.

11. Kim JH, Chin HM, Hwang SS, Jun KH. Impact of intra-abdominal fat on surgical outcome and overall survival of patients with gastric cancer. Int J Surg 2014;12(4):346-52.

12. Zhang L, Xu A, Han W, Wei Z, Xiong M, Yang W, Hu K. [Effect of body mass index on postoperative outcomes in patients with gastric cancer]. Zhonghua Wei Chang Wai Ke Za Zhi 2016;19(3):296-9.

13. Li B, Zhang HL. Effect of body mass index on postoperative prognosis of gastric cancer patients. J Prac Med 2015;31(10):1620-3.

14. Wong J, Rahman S, Saeed N, Lin HY, Almhanna K, Shridhar R, Hoffe S, Meredith KL. Effect of body mass index in patients undergoing resection for gastric cancer: a single center US experience. J Gastrointest Surg 2014;18(3):505.

15. Stang A.Critical evaluation of the Newcastle-Ottawa scale for the assessment of the quality of nonrandomized studies in meta-analyses. Eur J Epidemiol 2010;25(9):603-5.

16. World Health Orgnization (WHO). Physical status: the use and interpretation of anthropometry. Report of a WHO Expert Committee. World Health Organization technical report series 1995;854:1-452.

17. Wells GA, Shea B, O’Connell D, Peterson J, Welch V, Losos M, Tugwell P. The Newcastle-Ottawa Scale (NOS) for assessing the qual- 
ity of nonrandomised studies in meta-analyses. The Ottawa Hospital Research Institute: Ottawa.

18. Sinicrope FA, Foster NR, Sargent DJ, O'Connell MJ, Rankin C. Obesity is an independent prognostic variable in colon cancer survivors. Clin Cancer Res 2010;16(6):1884-93.

19. Dawood S, Broglio K, Gonzalez-Angulo AM, Kau SW, Islam R, Hortobagyi GN, Cristofanilli M. Prognostic value of body mass index in locally advanced breast cancer. Clin Cancer Res 2008;14(6):171825.

20. Dhar DK, Kubota H, Tachibana M, Kotoh T, Tabara H, Masunaga R, Kohno H, Nagasue N. Body mass index determines the success of lymph node dissection and predicts the outcome of gastric carcinoma patients. Oncology 2000;59(1):18-23.

21. Tokunaga M, Hiki N, Fukunaga T, Ohyama S, Yamaguchi T, Nakajima T. Better 5-year survival rate following curative gastrectomy in overweight patients. Ann Surg Oncol 2009;16(12):3245-51.

22. Laviano A, Meguid MM, Inui A, Muscaritoli M, Rossi-Fanelli F. Therapy insight: Cancer anorexia-cachexia syndrome--when all you can eat is yourself. Nat Clin Pract Oncol 2005;2(3):158-65.

23. Fukuda Y, Yamamoto K, Hirao M, Nishikawa K, Maeda S, Haraguchi N, Miyake M, Hama N, Miyamoto A, Ikeda M, Nakamori S, Sekimoto M, Fujitani K, Tsujinaka T. Prevalence of malnutrition among gastric cancer patients undergoing gastrectomy and optimal preoperative nutritional support for preventing surgical site infections. Ann Surg Oncol 2015;22 Suppl 3:S778-85.

24. Ejaz A, Spolverato G, Kim Y, Poultsides GA, Fields RC, Bloomston M, Cho CS, Votanopoulos K, Maithel SK, Pawlik TM. Impact of body mass index on perioperative outcomes and survival after resection for gastric cancer. J Surg Res 2015;195(1):74-82.

25. Minami Y, Kawai M, Fujiya T, Suzuki M, Noguchi T, Yamanami H,
Kakugawa Y, Nishino Y. Family history, body mass index and survival in Japanese patients with stomach cancer: a prospective study. Int $\mathrm{J}$ Cancer 2015;136(2):411-24.

26. Chen HN, Chen XZ, Zhang WH, Yang K, Chen XL, Zhang B, Chen ZX, Chen JP, Zhou ZG, Hu JK. The impact of body mass index on the surgical outcomes of patients with gastric cancer: a 10-year, single-institution cohort study. Medicine (Baltimore) 2015;94(42):e1769.

27. Yasunaga H, Horiguchi H, Matsuda S, Fushimi K, Hashimoto H, Ayanian JZ. Body mass index and outcomes following gastrointestinal cancer surgery in Japan. Br J Surg 2013;100(10):1335-43.

28. Zheng HL, Lu J, Zheng CH, Li P, Xie JW, Wang JB, Lin JX, Chen QY, Lin M, Tu RH, Huang CM. Short- and long-term outcomes in malnourished patients after laparoscopic or open radical gastrectomy. World J Surg 2018;42(1):195-203.

29. Mullen JT, Davenport DL, Hutter MM, Hosokawa PW, Henderson WG, Khuri SF, Moorman DW. Impact of body mass index on perioperative outcomes in patients undergoing major intra-abdominal cancer surgery. Ann Surg Oncol 2008;15(8):2164-72.

30. Nozoe T, Kohno M, Iguchi T, Mori E, Maeda T, Matsukuma A, Ezaki T. Analysis of the impact of the body mass index in patients with gastric carcinoma. Surgery today 2012;42(10):945-9.

31. Ha GS, Kim YW, Choi EH, Kim IY. Factors associated with the lack of adjuvant chemotherapy following curative surgery for stage II and III colon cancer: a Korean national cohort study. Anticancer Res 2017;37(2):915-22.

32. Migita K, Takayama T, Matsumoto S, Wakatsuki K, Tanaka T, Ito M, Kunishige T, Nakade H, Nakajima Y. Impact of being underweight on the long-term outcomes of patients with gastric cancer. Gastric Cancer 2016;19(3):735-43. 